\title{
Energy analysis via value stream mapping: a case study of an automotive weld plant
}

\author{
Keshav Ramsunder* Oludolapo Olanrewaju ${ }^{\dagger}$
}

Received: 11 September 2020; Revised: 29 November 2021; Accepted: 17 December 2021

\begin{abstract}
Over the past few decades, lean manufacturing has been the pinnacle of strategies applied for cost and waste reduction. However, as the search for competitive advantage and production growth continues, there is a growing consciousness toward environmental preservation. With this consideration in mind this research investigates and applies value stream mapping techniques to aid in reducing environmental impacts of manufacturing companies.

The research presented is based on empirical observation within the chassis weld plant of a company which we refer to as Company X. Company X falls within the automotive sector with its primary efforts in the manufacturing of light trucks and pick up vehicles; focusing on weld operations and utilizes the cross member line of auxiliary cross as a point of study. The utilization of a mass flow meter and power logger allowed for the data collection of emissions emitted by the weld and service equipment. The data was thereafter visualised via environmental value stream map using an 8 -step method. The environmental value stream map visually illustrated that the total lead-time to build an auxiliary cross is 16.7 minutes and during this process, $0.9945 \mathrm{KgCO}_{2}$ is emitted. We identify the stage at which the highest cycle time and carbon emissions emitted; this and provides a starting point for the investigation of emission reduction activity. The environmental value stream map aids in the development of a method that allows quick and comprehensive analysis of energy and material flow. The results of this study are important to practitioners and academics as it provides an extension and capability of lean manufacturing tools. Further, the environmental value stream map provides a gateway into realising environmental benefits and sustainable manufacturing through lean manufacturing.
\end{abstract}

Key words: Chassis weld; environmental value stream map; environmental impacts; lean manufacturing; sustainable manufacturing; value stream mapping

*Department of Industrial Engineering, Faculty of Engineering and the Built Environment, Durban university of Technology, Durban, South Africa, email: keshavramsunder@ymail.com

${ }^{\dagger}$ Department of Industrial Engineering, Faculty of Engineering and the Built Environment, Durban university of Technology, Durban, South Africa, email: oludolapo0@dut.ac.za 


\section{Introduction}

Over the past few decades, lean manufacturing (LM) has been the pinnacle of strategies applied for cost and waste reduction. Developed specifically for the Toyota Production System (TPS), LM is a popular instrument that is used in present day manufacturing industry and service sectors. However, as the world continues to progress, there is a growing consciousness towards environmental preservation. Industries are constantly pressured to minimize negative environmental impacts and conserve energy when products are manufactured. This translates to the need for sustainable products and the adoption of more sustainable manufacturing practices.

On one hand, researchers and practitioners have developed strategic tools that promote sustainable manufacturing. These include 3R, ISO 14001 and Life Cycle Assessment. However, these pose more of a catalyst effect to an existing manufacturing system; see [3], [4] and [7]). On the other hand, a large number of authors suggest a good starting point for the development of better strategies for sustainable operations, is to use best practices and analyse how they can be adapted; see [6], [28] and [8].

With the mass utilization of LM around the world, [22] has investigated, both theoretically and empirically, the "greening" of the process utilizing LM techniques. In this regard, a critical lean tool, value stream mapping (VSM), is not only used to identify the seven LM wastes, but also recognises environmental impacts. Hence, the goal of this paper is to apply VSM to an existing manufacturing process, develop environmental process metrics, and highlight high waste areas that lean wastes can be improved. The following section presents a review from various studies on VSM. Section 3 details the practical testing of the theoretical findings, which is the methodology. Observation and discussion follow in Section 4 while Section 5 concludes.

\section{Literature review}

VSM is a visual based method that illustrates, identifies and measures wastes that result from inefficiencies of equipment, information, time and material during the production process; see [1]. Numerous papers have displayed the implementation of lean techniques and highlight that VSM has been a stepping stone to the successful reduction of waste. Previous studies analysed the production flow of an automotive component manufacturing using LM techniques. The application of VSM identified excessive wastes in the form of rejects and inventory. Using additional lean tools, the authors were able to improve productivity while reducing rejects rates as well as inventory. [23] found that by performing VSM studies within the colour industry achieved a non-value adding time of 68 minutes and a lead-time of 8 days. Focusing on these aspects with LM tools, such as continuous improvement and cycle time evaluation, resulted in a $20 \%$ and $46 \%$ reductions in lead and non-value adding time respectively. [21] employed VSM to identify wasteful activities within an electronics assembly line. The study highlighted potential benefits in lead time, labour reduction and floor space saving.

The frameworks for the conventional VSM have been well established and emphasised, corresponding to benefits. The literature thus far has mentioned a few applications; 
there are many more papers and studies carried out that demonstrates the conventional application of VSM. However, the focus of this paper is to examine how the principles of VSM can be extended to support sustainability and environmental performance. The work of [10], proposed the environmental value stream mapping (EVSM) approach. The concept made use of VSM practices with the aim to improve energy efficiency in the manufacturing sectors. The authors realized EVSM to be a graphical technique that identifies energy use and were thereby able to plan out saving opportunities at each step of the process. [2] used EVSM in the biodiesel sector as a tool to analyse and find negative energy impacts within their manufacturing process. Through the EVSM, the authors were able to reduce non-value adding processes and design one that saves energy and reduces production costs.

Similarly, [20] presented the mapping of energy consumption in their Computer Numerical Controlled machining processes. The paper consisted of experimental data that verified their mathematical logic and showed that energy use at each process can be used for multi-criteria planning systems to validate consumption. The paper of [18] demonstrated that with the addition of time and energy onto a VSM, it was possible for VSM to address two factors under the same application. The paper went on to show the application of EVSM on global supply chains. The inclusions of transport allows one to evaluate the non-value adding energy requirements within the value stream of the supply chain. [27] utilized EVSM and demonstrated it to be an effective way for management to functionally address problems of production materials.

The literature review presented above has outlined the benefits of the contemporary VSM and how the fundamentals can be applied in support of identifying environmental impacts. The work carried out by the various authors mentioned, emphasize that VSM is one of the LM best practices as it not only maps production wastes but also environmental wastes. The review of the literature has allowed a key theoretical finding to emerge. This can be summed up to be that VSM can be used as a tool for mapping and identifying environmental impacts in the processes of plant layout.

\section{Methodology}

In this section, the background of the case study is provided. In addition, the preliminary experiment that details the first measurement of the $\mathrm{C}_{2}$ contributors is discussed. This is followed by the methods that will be used to construct the EVSM.

\subsection{Background}

The study took place in the chassis manufacturing plant of Company X; an automotive manufacturer focusing on the manufacturing of light trucks and pick up vehicles. The chassis manufacturing plant's core function is the assembly and welding of chassis frames. The plant currently has an output volume of 420 units per day and utilizes 347 welders. Each day is divided into a two-shift pattern and run a day and night shift that amount to 7.5 hours each.

A chassis frame, as illustrated in Figure 1, consists of side rails and cross members. The frame forms the skeleton structure and holds all major components of the vehicle together. 
The chassis frames are built on a production line called the chassis main line. The line begins with the assembly of chassis rails that are welded progressively stage by stage using using a combination of manual and automated welding techniques.

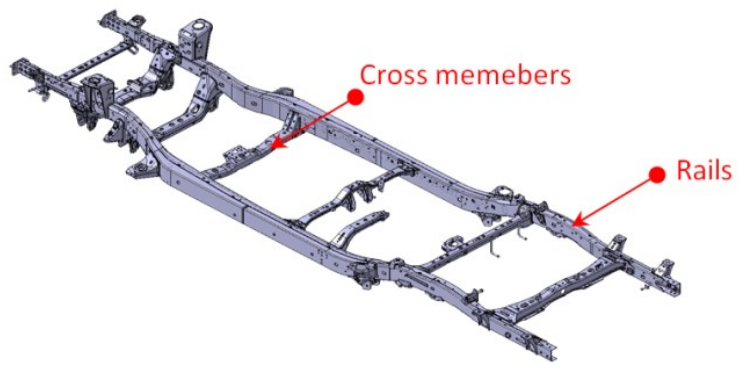

Figure 1: Diagram of chassis.

On a separate manufacturing line, the cross members are fabricated and transported to the chassis main line. Using a "marriage" fixture, the cross members and rails are assembled and welded together. The gas metal arc welding process is used within the plant, as it is known for achieving high productivity with good quality results; see [9].

The cross member and chassis mainline build 27 different derivatives that support multiple model builds of light truck/pickup vehicles. The cross member line builds seven types of cross members to cater for different functional areas of the vehicle and support model variation. These include suspension, drive train, and body mounting specifically.

The production line under consideration is the auxiliary cross production cell and is depicted in Figure 2. This was selected for the following reasons:

- Auxiliary cross is fitted to all chassis models irrespective of derivative.

- There is a combination of assembly, manual and automated welding in the manufacturing process.

- Based on previous observation, there is a high inventory of finished goods.

- Based on previous observation, there is an over production condition.

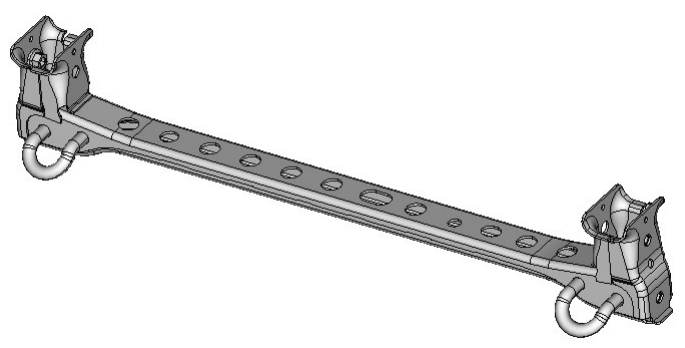

Figure 2: Auxiliary cross member. 


\subsection{Preliminary work - experiment 1 of 2}

In order to test the feasibility of the study, preliminary work in the form of a pre-test was conducted to determine if the methodology adopted would meet the objectives of the study. Pre-testing is the first measure of the dependent variable.

Acknowledging the above, a pre-test was done on the auxiliary cross member. A crucial part for the experiments to take place was the identification of major $\mathrm{CO}_{2}$ contributors. Listing the services of the equipment in each process resulted in the following three key $\mathrm{C}_{2}$ contributers.

\section{Compressed Air Usage}

Compressed air is essential in order to supply process requirements and to operate pneumatic equipment. It is relatively costly to generate and consume a great share of total energy consumption in this industry; see [16]. Similarly, the company X utilises compressed air in order to operate the weld fixtures. The weld fixtures make use of pneumatic equipment that include cylinders to clamp and hold components in place during the welding process. Hence, the measurement of compressed air is required as it is a vital resource in the process operation.

\section{Electricity consumption}

The manufacturing community is a significant $\mathrm{CO}_{2}$ emission contributor due to the intense use of energy for industrial operations. Most of this energy in manufacturing is supplied in the form of electricity; see [5]. The welding procedure, the core function of the plant, is a considerable consumer of electricity. Additionally, the supply of compressed air ultimately contributes to the use of electricity.

\section{Shield gas for weld operations}

The function of shield gas that is used in the welding process significantly effects the weld integrity, seam appearance, mechanical property and fume emission; see [19]. The plant utilizes a shield gas mixture of $\mathrm{CO}_{2}$ and argon to protect the weld pool against contamination that could generate defects. The shield gas is a direct emitter of $\mathrm{CO}_{2}$ into the environment, and the consumption will therefore be measured.

\subsubsection{Pre-test study}

Figure 3 depicts the visualisation of the $\mathrm{C}_{2}$ contributors by equipment type. The nut welding stage (LWR x NUT) does not make use of shield gas, as it is a form of resistance spot welding. The inspection stage does not have a pneumatic weld fixture, but rather a weld table. Therefore, it does not make use of compressed air.

The operators and production standard equipment were utilized for this test. There was a concern that the operators will not understand the objective of the pre-test and in turn affect the internal and external validity of the study. Therefore, the objective of the study 


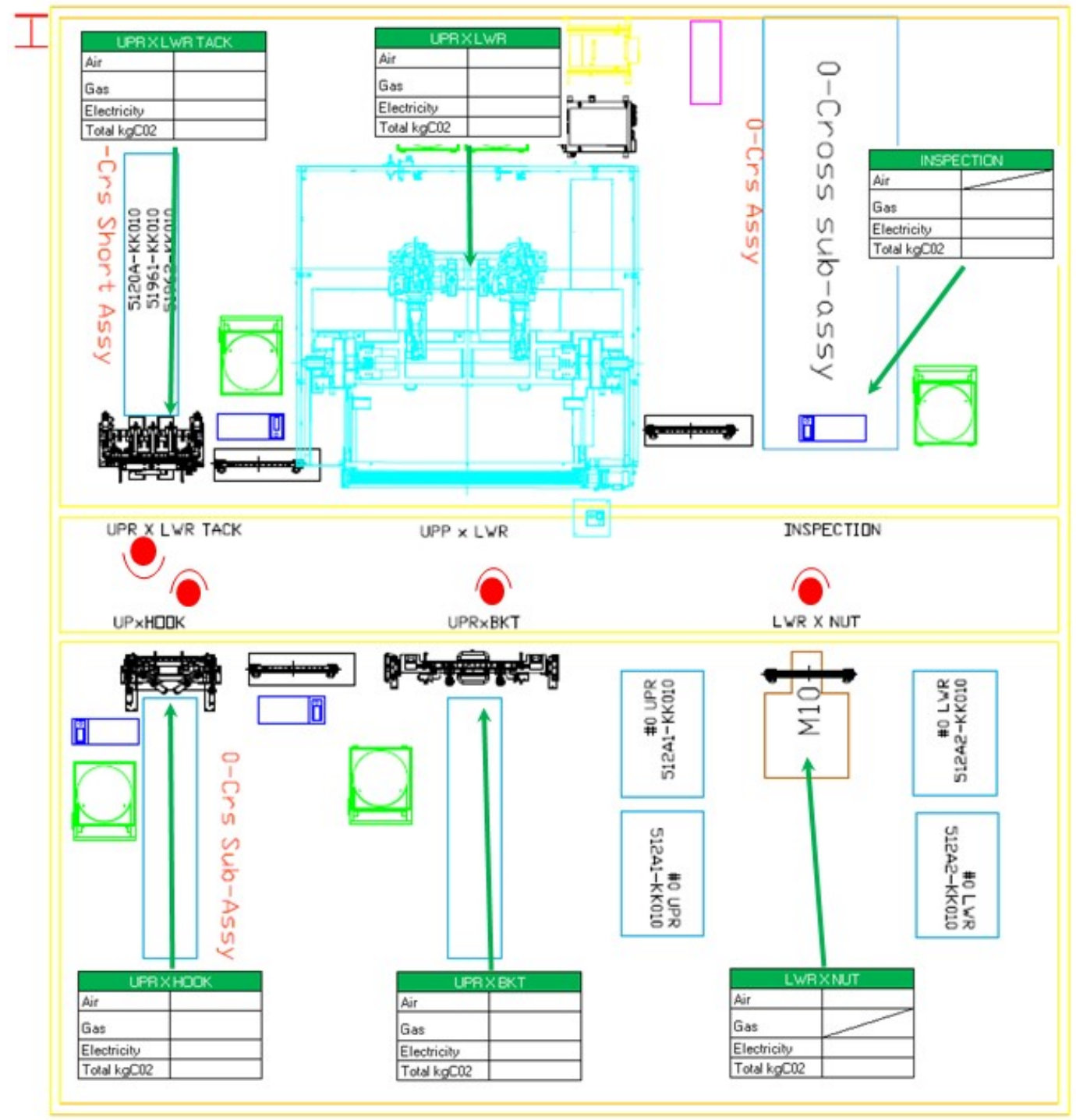

Figure 3: Auxiliary cross member and $\mathrm{C}_{2}$ contributors.

was presented to the operators to clarify any doubts. The pre-test study was conducted over a 1 month period and consisted of the following.

\section{a. Process analysis as well as a cycle time study for online operators and automated equipment}

The cycle time study and process analysis will be based on the current work operation and will serve as the base data for the EVSM application. The procedure consists of 2 stages. During stage 1, all data regarding the process were collected. This includes production forecast, process plans, and part assembly specification. Stage 2 involves the measurement of cycle time for each operator including the automated stages. The production line takt is calculated by dividing the monthly customer demand and the available time in a 
production shift;

$$
\text { Takt time }=\frac{\text { Available production time }}{\text { Production demand }}
$$

\section{b. Measurement of emissions generated by identified services}

Various measurement tools were utilized to extract the current data of the emissions generated by the identified equipment and services. This will serve as the base data for the EVSM application.

\subsubsection{Measuring instruments}

The environmental impacts making up the dependent variable have been identified as compressed air, electricity as well as shield gas emissions. During an energy audit process, clamp-on power meters, tachometers and mass flow meters were found to be some of the most effective measurement and auditing instruments; see [25]. In line with this study, similar types of tools have been used to measure the environmental impacts. These are broken down further in Table 1. The table includes the entity being measured, the tool used to measure and lastly the unit of measurement.

\begin{tabular}{lll}
\hline \hline Entity & Measurement Tool & Unit of measurement \\
\hline Gas emissions & Mass flow meter & $\mathrm{KgCO}_{2}$ \\
Compressed air & Mass flow meter & $\mathrm{Kg}$ \\
Electricity & Clamp on power Logger & $\mathrm{Kwh}$ \\
Time & Stop Watch & seconds \\
\hline
\end{tabular}

Table 1: Measuring instruments breakdown.

The weld fixtures pnuematic equipment run on a maximum of 6 bar compressed air pressure. Company X currently utilizes a Proline T-Mass 65 by Endress + Hauser for all mass flow measurements. The meter has the ability to measure air, gas, oxygen, nitrogen, carbon dioxide and argon. Given that the meter has the ability to measure a range of gases, the shield gas will be measured in the same manner. Electricity is required for the use of the arc welding machines as well as the automated welding stages. A clamp on power logger will be used to measure the electricity consumption of these facilities. Company X makes use of a Hioki Clamp on Hitester unit. These units have the ability to read 3 phase power systems and have the ability to adequately measure the weld facilities.

\subsubsection{Data collection methods}

The data was collected using the specified measuring instruments over the 26 samples for the $\mathrm{CO}_{2}$ emitters. The data was averaged, acquiring the mean emission generated per process. Once the mean for each $\mathrm{CO}_{2}$ emitter had been calculated per process, a common unit of measure was established to support the interpretation and judging criteria. The total amount of GHG emissions produced directly and indirectly is known as the carbon footprint and is commonly measured in kilograms of carbon dioxide $\left(\mathrm{KgCO}_{2}\right)$; see [15]. 
With this in mind, the following was taken into account when commonizing the unit measured.

\section{Compressed Air Consumption}

The Endress Hauser meter provides the results in a unit measure of normal cubic meters per hour $\left(\mathrm{Nm}^{3} / \mathrm{hr}\right)$. However, the GHG emission takes place at the plant compressor unit. Therefore, the unit provided by the meter will need to be converted to kilowatt-hour (kWh) and thereafter $\mathrm{KgCO}_{2}$. The compressor efficiency factor is 0.155 on the plants compressor housing and relates to the electricity consumption. Multiplying this constant to meter readings, the power consumption in kilowatts per hour is achieved;

$$
N m^{3} / h r \times 0.155=k W h .
$$

In order to achieve the unit of $\mathrm{KgCO}_{2}$, the carbon dioxide emission factor specific to South Africa's energy provider, Eskom, needs to be understood. The emission factor, based on a study of three of the country's base-load coal fired power stations was calculated to be $0.955 \mathrm{KgC0}_{2}$ per $\mathrm{kWh}$ electricity generated (see [13]);

$$
k W h \times 0.955 \mathrm{KgCO}_{2} / k W h=\mathrm{KgCO}_{2} .
$$

Based on the above formula and constants, the compressed air consumption can be represented as kilogram of carbon dioxide $\left(\mathrm{KgCO}_{2}\right)$.

\section{Electricity usage}

The clamp on power logger provides results already in a unit measure of $\mathrm{kWh}$. Following the same line of thinking, converting to $\mathrm{KgCO}_{2}$ would be the same as described in the compressed air consumption section.

\section{Shield gas consumption}

The Endress Hauser meter was once again utilized, however it was calibrated to yield mass flow in a unit of measure of $\mathrm{KgCO}_{2}$. Therefore, the results acquired did not need any conversion and were hence used in the measured format.

\subsection{Value stream mapping - experiment 2 of 2}

The primary goal of VSM is to find different forms of waste and try to eliminate them; see [24]. Further to this, the literature review demonstrated that VSM can be implemented to identify the environmental impacts of each process of the plant layout.

Drawing a VSM map should follow a standard procedure so that all required data are captured; see [3], [14] and [12]. Figure 4 highlights the following steps that were carried out.

Steps 1 through 6 highlight the standard VSM procedure, while steps 7 and 8 supplement the map with environmental data. In order to reduce any misconception or ambiguity, the 


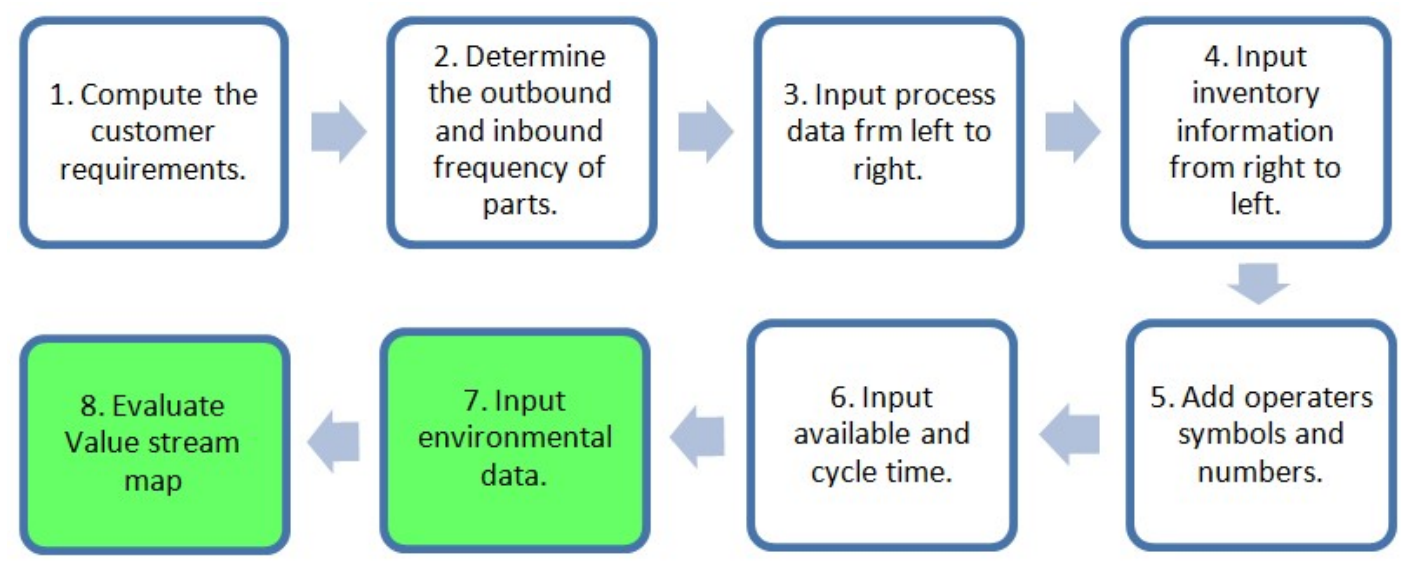

Figure 4: Diagram of chassis.

VSM was done by online observation. The input of the data allowed for the visualisation of lean waste within the process as well as high consuming energy areas. The results of this experiment will support the theoretical findings relating to VSM.

\section{Observation and discussion}

This section presents the results as well as a discussion of the experiments outlined in the methodology. The section begins with the preliminary experiment that includes pre-testing and data collection. The EVSM is thereafter created and discussed.

\subsection{Pre-test data collection}

\section{Process analysis and cycle time}

The procedure begins by understanding the components used to build the assembly and the sequenced process of the assembly.

\section{Process analysis}

\begin{tabular}{llll}
\hline \hline Serial no & Part no & Part name & Qty \\
\hline 1 & 512A1-KK010 cross member & frame auxiliary, UPR & 1 \\
2 & 512A2-KK010 cross member & frame auxiliary, LWR & 1 \\
3 & 5120A-KK010 gusset sub-assy & frame auxiliary C/MBR, RH & 2 \\
4 & 51961-KK010 hook & FR & 2 \\
5 & 51962-KK010 retainer & FR hook & 2 \\
6 & $90174-$ T0004 nut & weld & 6 \\
\hline
\end{tabular}

Table 2: Auxiliary cross member bill of materials.

Figure 5 and Table 2 illustrate the exploded view of the auxiliary cross member as well as the bill of materials. There are 14 components required to complete the assembly. The exploded view provides an image of the orientation and assembly of the components. The 


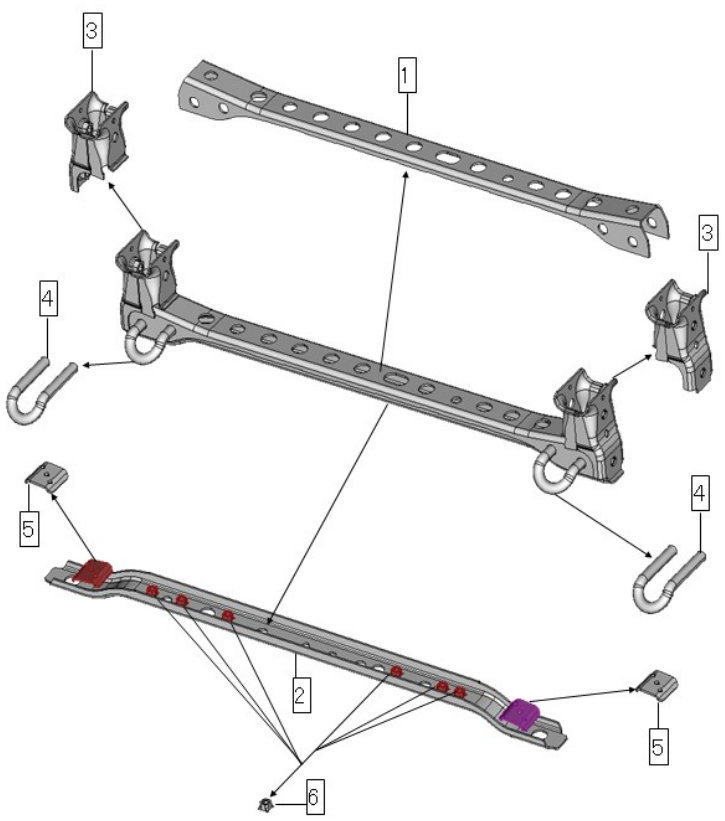

Figure 5: Exploded view of auxiliary cross member.

process plan further clarifies the assembly sequence of each component. The process plan is a preparatory step and draws attention to the sequence of operations. It is often used in manufacturing shops that make parts of the same kind on a frequent basis; see [20]. The process plan for the auxiliary cross member is shown below.

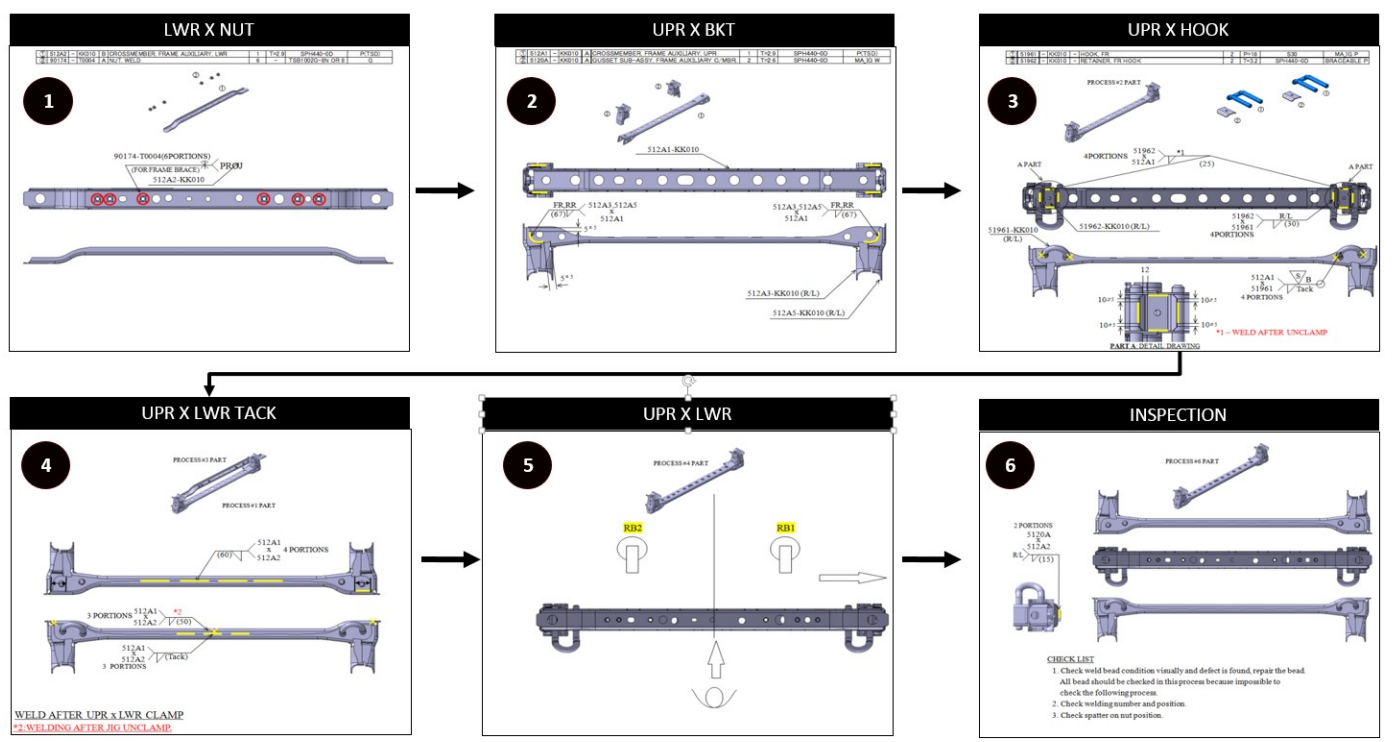

Figure 6: Auxiliary cross process plan.

The process plan in Figure 2 highlights the series of steps that was followed to complete the weld operation of auxiliary cross member. The process is made up of a total of 6 stages. Stage 1, LWR X NUT, involves the welding of 6 threaded nuts to the lower stamped 
panel and thereafter moves to a work in process stand at Stage 4. Stage 2, UPR X BKT, includes the assembly and welding of a left and right bracket. The stage 2 processed part thereafter moves to stage 3, UPR X HOOK, and involves addition of 2 hook brackets. Stage 4, UPR X LWR TACK, consists of the assembly and tack welding of the stage 1 and stage 3 part. Stage 5, UPR X LWR, is an automated weld process and completes the remaining welding. The final stage, INSPECTION, is a quality check within the process to ensure that correct parts are fitted and the rework of any weld defects.

Each stage details the specific parts and respective quantities of the assembly process and the required weld elements. These key points provide fundamental information to help ensure that the quality requirement is met at the optimum cycle time.

\section{Cycle time and production demand}

Utilizing supply chain production planning methods, demand planning can be forecasted for manufacturing volume purposes; see [17]. This is comparable to the manufacturing volume of Company $\mathrm{X}$ as the forecasted volumes are based on the sales information provided by the dealerships. Through the marketing and sales as well as the production planning departments, this information is thoroughly analysed before forecast generation. The information below was obtained from the production planning department.

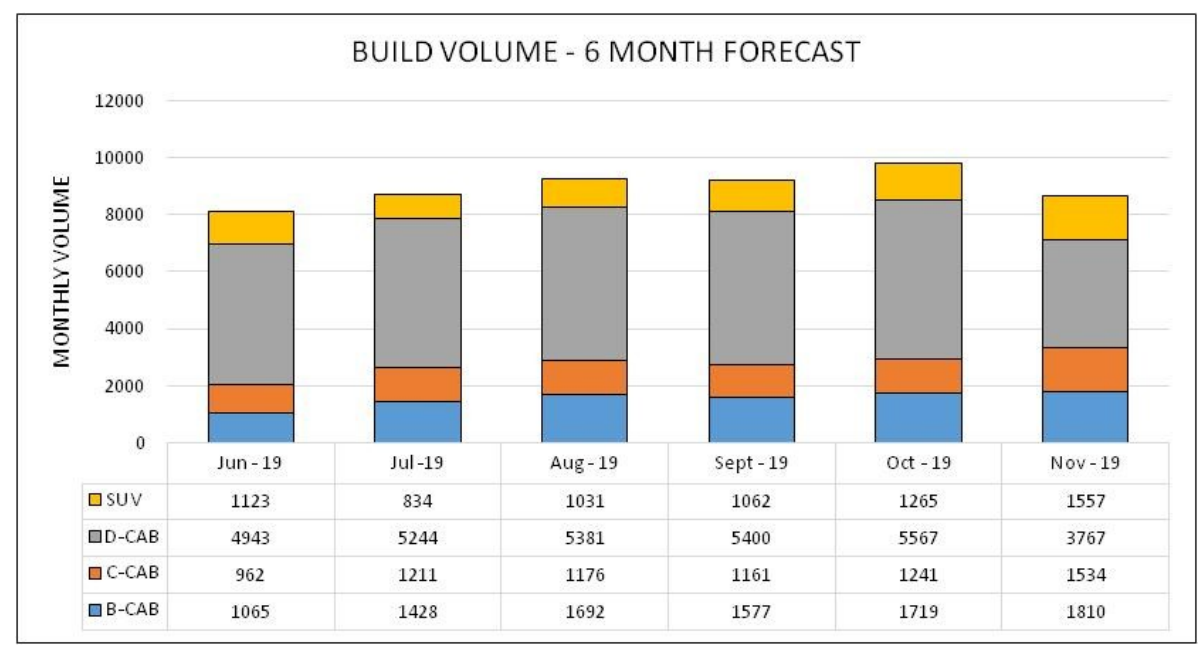

Figure 7: Month volume forecast.

The monthly volumes by IMV model type is illustrated in Figure 7. The average volume per month is 8958 units. As mentioned in the methodology, the auxiliary cross is required for all model types. Hence, the total volume represents the production demand. The assembly and components, process plan and production demand helped to conceptualize the requirements of the line. The information additionally supported Step 2 in the calculation of takt and cycle times. 


\section{Takt time calculation}

Takt and cycle times are imperative elements in improving productivity, reducing cost and improving customer response; see [11]. It therefore provides a visualisation of the production line capability, which forms the base for improvements to take place.

Stage 1 highlighted the production volume, which was used to calculate the takt time via (1). The production shift is 7.5 hours of working time and this equates to 450 minutes. The monthly volume per day will need to be calculated to volume per shift via the following formula;

$$
\text { Volume per shift }=(\text { Monthly volume }) /(\text { No of days in a month } \times 2) \text {. }
$$

Since there are 2 shifts in a working day, the formula has a division of 2 . Table 3 demonstrates the use of these formulas.

\begin{tabular}{lrrrrrr}
\hline \hline & Jun & Jul & Aug & Sept & Oct & Nov \\
\hline Body and chassis type & & & & & & \\
Total monthly volume & 8093 & 8717 & 9280 & 9199 & 9792 & 8668 \\
No. of days per month & 20 & 23 & 22 & 21 & 23 & 21 \\
\hline Takt calculation & & & & & & \\
Product demand shift & 203 & 190 & 211 & 220 & 213 & 207 \\
Takt time & 2.22 & 2.37 & 2.13 & 2.05 & 2.11 & 2.18 \\
\hline
\end{tabular}

Table 3: Monthly takt time calculation.

The takt varies as the market demand changes from month to month. In this case, the lowest takt is used to ensure the production lines have enough flexibility to adjust to the demand variation.

The takt of 2.05 minutes or 123 seconds is the time required for a unit to be produced at the end of the manufacturing process. Therefore, in order to meet the requirement, Chassis Plant $\mathrm{X}$ will require a lower takt process. A standard process within the plant is to reduce 6 seconds in delivery time resulting in an overall takt time of 117 seconds.

Figure 8 compares the mean cycle times to the takt time of the production line. The graphic representation helps in the understanding of the line performance. Currently all operators are below the takt line, which illustrates that there are no bottlenecks and the production line can adequately manufacture the required volume.

\subsection{Measurement of emissions generated}

The measurement of the services resulted in the following readings. A total of 26 readings for each of the $\mathrm{CO}_{2}$ contributers were observed and the averages were tabulated in Table 4. In the case of compressed air, the power consumption by the plant compressor was calculated using the compressor efficiency factor as per (2) and thereafter converted to an electricity emission using (3). The equipment electricity usage was measured, and the electricity emission calculated via (3). Finally, the shield gas, which is a direct emission of $\mathrm{C}_{2}$, was observed and tabulated. 


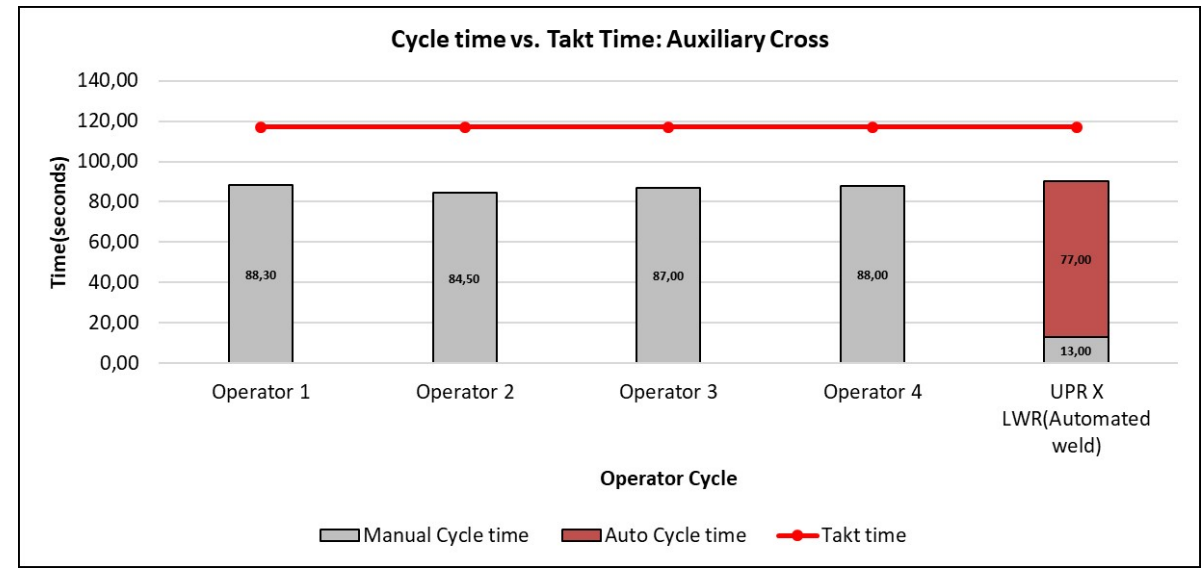

Figure 8: Cycle time vs Takt time.

This section has highlighted the collection of process data through cycle time measurement and takt time calculations. Additionally, the section has demonstrated the measurement of emissions in the form of compressed air usage, electricity and shield gas. The section to follow details the use of the data on the construction of the EVSM.

\subsection{Generation of EVSM}

The literature review has demonstrated that a VSM can be implemented for identifying the environmental impacts of a process within a plant layout. The value stream in Figure 9 below illustrates the current state of the auxiliary Cross manufacturing process.

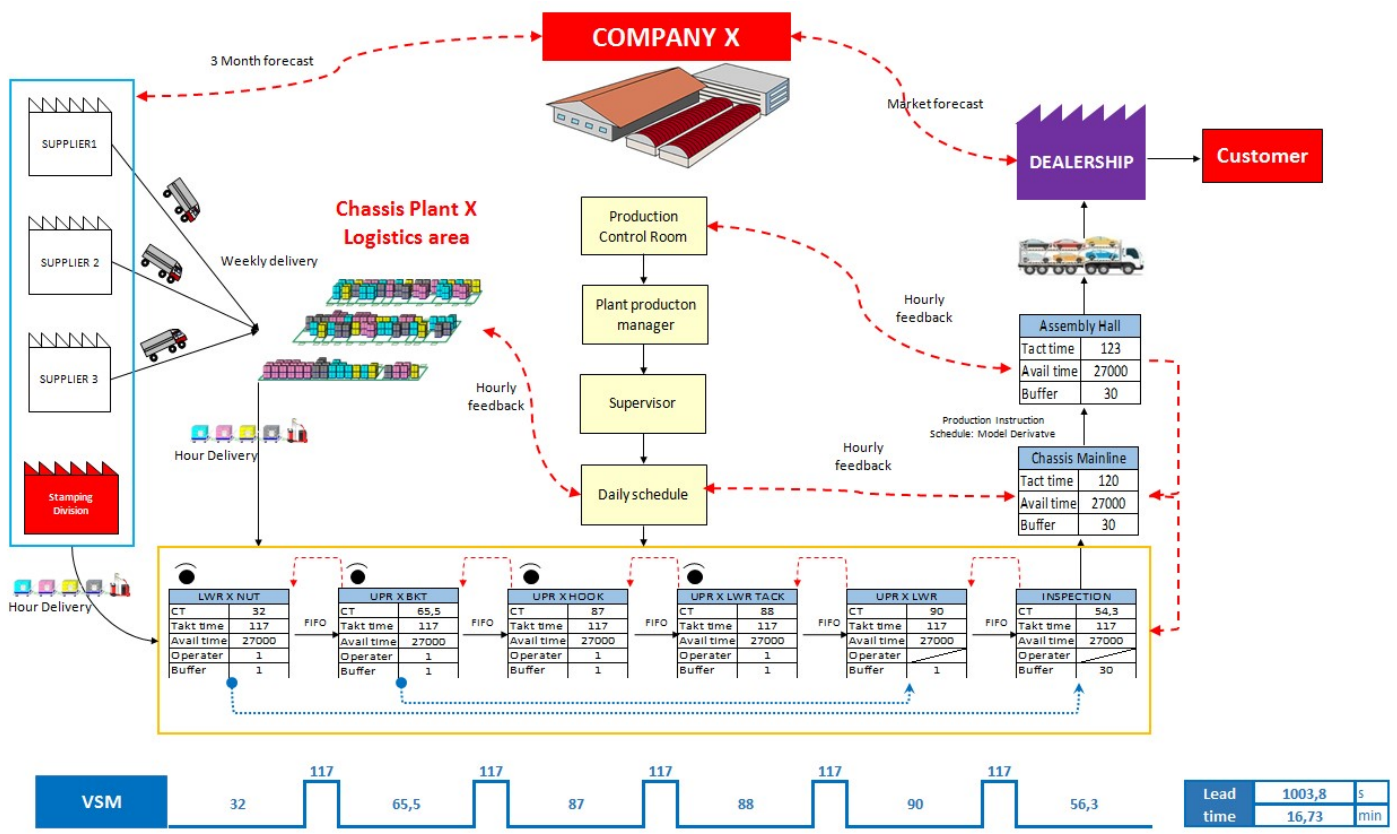

Figure 9: Auxiliary cross member current state VSM. 


\begin{tabular}{lrrr}
\hline \hline Process & $\begin{array}{r}\text { Compressed air } \\
\text { readings }\left(\mathrm{Nm}^{3} / \mathrm{h}\right)\end{array}$ & $\begin{array}{r}\text { Compressor power } \\
\text { consumption }(\mathrm{kWh})\end{array}$ & $\begin{array}{r}\text { Electricity } \\
\text { emission }\end{array}$ \\
\hline Compresses air usage & & & \\
LWR X NUT & 0.053 & 0.0081 & 0.0078 \\
UPR X BKT & 0.056 & 0.0087 & 0.0084 \\
UPR X HOOK & 0.011 & 0.0017 & 0.0016 \\
UPR X LWR TACK & 0.267 & 0.0414 & 0.0396 \\
UPR X LWR & 0.234 & 0.0362 & 0.0347 \\
INSPECTION & & & \\
Total & 0.620 & 0.0962 & 0.0921 \\
\hline Electricity usage & & & 0.0193 \\
LWR X NUT & & 0.0202 & 0.0235 \\
UPR X BKT & 0.0245 & 0.0241 \\
UPR X HOOK & & 0.0252 & 0.0262 \\
UPR X LWR TACK & & 0.0274 & 0.1111 \\
UPR X LWR & 0.1160 & 0.0024 \\
INSPECTION & & 0.0025 & 0.2067 \\
Total & & 0.2158 & \\
\hline Shield gas usage & & & 0.004 \\
LWR X NUT & & & 0.033 \\
UPR X BKT & & & 0.033 \\
UPR X HOOK & & & 0.051 \\
UPR X LWR TACK & & & \\
UPR X LWR & & & \\
INSPECTION & & & \\
Total & & & \\
\hline
\end{tabular}

Table 4: Environmental readings from service facilities.

The process begins with a market forecast that is acquired from the dealership sales statistics. The statistics include the monthly sales figures of model and vehicle type. Based on these statistics, the production planning department project the volumes and the production control room (PCR) developed a 3 month plan. The 3 month plan is sent to external supplier as well as each manufacturing plant within Company X. The plan is further broken down and the daily projected volumes are planned into the operation. This forms the first two steps outlined in the methodology, as the customer requirement is computed. Using the customer requirements data, the outbound and inbound frequency of parts can additionally be determined.

The external suppliers carry out a similar procedure within their planning departments and schedule weekly component delivery to correspond to Company X's visual management system. These components are delivered to Chassis Plant X's logistics areas and distributed to their required assembly areas. The stamping division is an internal supplier and provides press components for the weld assembly processes. The press shop is provided with a 3 month schedule as well, and the batch builds are scheduled accordingly. Due to the factories in separated locations of the plant, the parts are delivered via a tow motor. 
The manufacturing process of the auxiliary cross member is mapped using process data boxes. The process data boxes contain the cycle time (CT) in seconds, the takt time (in seconds), the available time (in seconds), number of operators in the stage and the minimum stock required which is usually termed buffer; see [14]. Each process is mapped as per the process sequence and flows through to the chassis mainline which supplies the assembly hall where final assembly of the vehicles take place. Steps 3 through to 6 of the VSM standard procedure have been carried out as mentioned in the methodology and summarized within the process data boxes. Observing the LWR X NUT stage, for example, it can be deduced that the CT is 32 seconds, the takt time is 117 seconds and the available time is 27000 seconds. Additionally there is one operator and one buffer in the stage respectively.

The objective of the value stream is to highlight the material flow, information flow and lead time for the product manufactured. Using this pictorial mapping technique, the inefficiencies of the system can be studied; see [26]. Applying the cycle times from experiment 1, the lead time ladder illustrates a 16.73 minute lead time before transportation to the mainline for chassis assembly. Before mapping the environmental impacts, the following assumptions were considered.

1. The environmental impacts consist of the manufacturing process of auxiliary cross member.

2. The chassis mainline and assembly hall impacts were not considered for this study.

3. The supplier impacts were not taken into consideration for this study.

4. The environmental effects from logistics and transport were not taken into account for this study.

Using the data obtained from experiment 1 and the findings of the literature review, the following environmental data were mapped into the current state of the VSM. Figure 10 demonstrates the EVSM for the current state of the process. Below the standard VSM process data boxes, the environmental data boxes have been included.

For instance, the environmental box for the UPR X BKT stage of the manufacturing process illustrates $0.0084 \mathrm{KgCO}_{2}$ of air was used, while $0.033 \mathrm{KgCO}_{2}$ and $0.0245 \mathrm{KgC0}_{2}$ was used for gas and electricity respectively. The sum of these figures results in a total of $0.0659 \mathrm{KgCO}_{2}$. These figures account for a single auxiliary cross member. Similarly, following the methodology steps 7 and 8, the environmental data has been mapped for all the processes within the auxiliary cross member line.

Just as VSM has a lead-time ladder, similarly Figure 11 highlights a carbon emissions ladder to illustrate the accumulation of emissions through the process. The ladder describes the emissions from the process, as well as the inventory stock or work in progress after the process. From this figure, it can be seen that $0.9945 \mathrm{KgC0}_{2}$ is emitted during the production of an auxiliary cross member. 


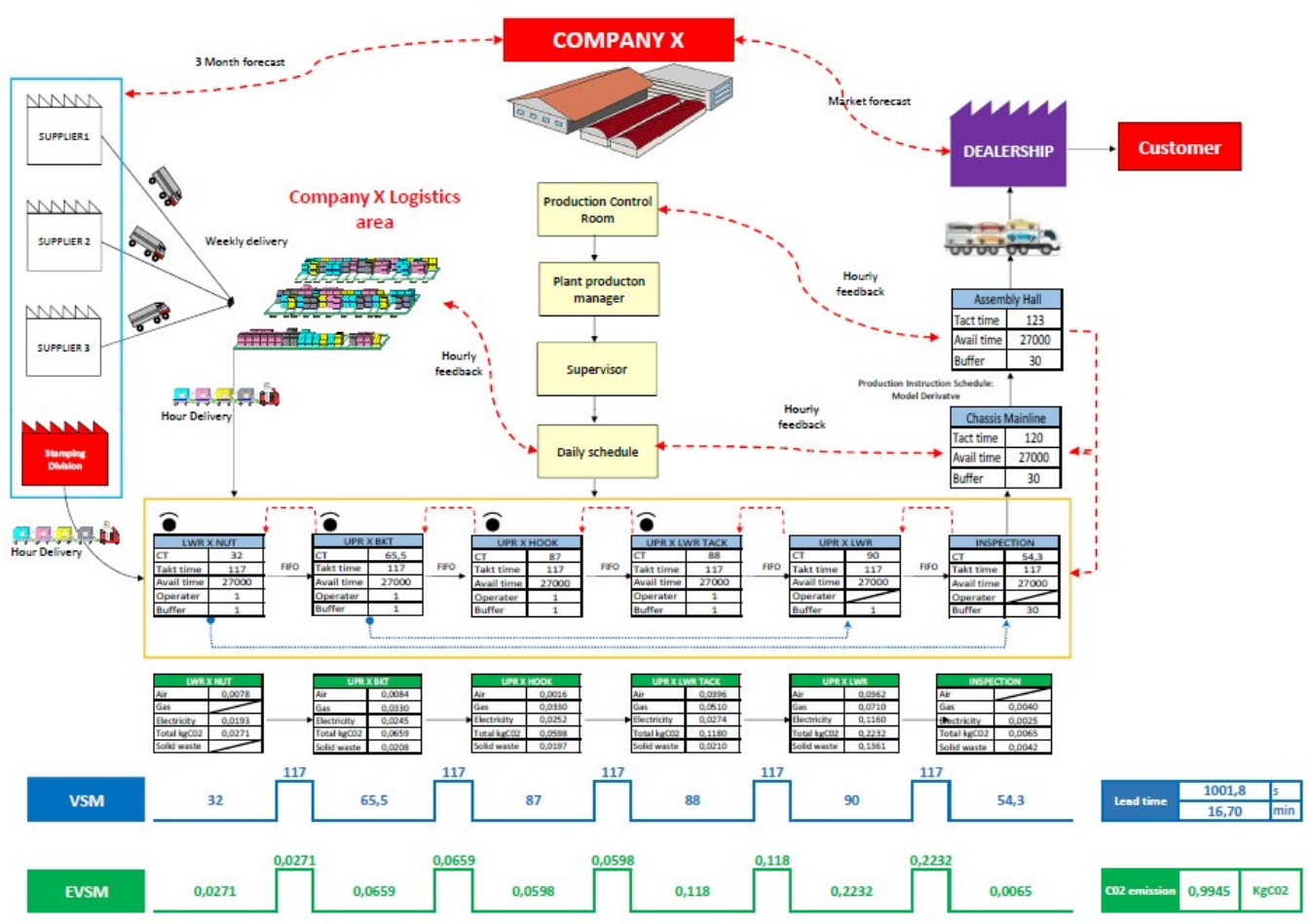

Figure 10: Auxiliary cross member current state EVSM.

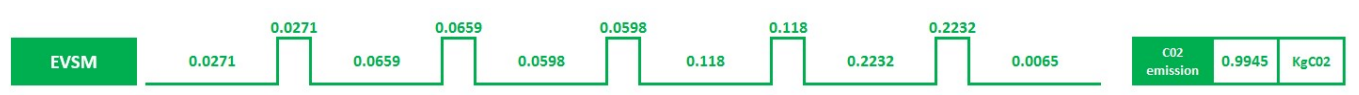

Figure 11: Carbon emissions ladder.

\section{Conclusion}

From the above results, it is evident that VSM can be used as a tool for mapping and identifying environmental impacts in a manufacturing process. The EVSM aids in the development of a method that allows quick and comprehensive analysis of energy and material flows. This allows for the theory that LM can lead to environmental benefits.

The experiment provides a gateway into environmental benefits achieved through LM that can be further explained. As more and more lean tools are applied to a process, the effects may be tracked using EVSM techniques. Additionally, it can aid in the design process of manufacturing operations by allowing the visualisation of each process effect. This will not only encourage environmental thinking, but also allow for the design of sustainable manufacturing.

The result of this research is also important to practitioners and academics as it provides insight to the extension and capability of lean tools. This will lead to LM being an investigable model for greening the production processes within the South African manufacturing industry. Practitioners can further the work presented in this study by implementing various lean tools, such as TPM, single minute exchange of die and cellular manufacturing to reduce the seven deadly wastes of lean and track the effects on the environment. 


\section{References}

[1] Arunagiri P and Gnanavelbabu A, 2014, Identification of high impact lean production tools in automobile industries using weighted average method, Procedia Engineering, 97, pp. 2072-2080.

[2] Chatterjee R, Sharma V, Mukherjee S and Kumar S, 2014, Value stream mapping based on energy and cost system for biodiesel production, International Journal of Sustainable Manufacturing, 3(2), pp. 95-115.

[3] ChIARINI A, 2014, Sustainable manufacturing-greening processes using specific lean production tools: an empirical observation from European motorcycle component manufacturers, Journal of Cleaner Production, 85, pp. 226-233.

[4] Fercoq A, Lamouri S and Carbone V, 2016, Lean/green integration focused on waste reduction techniques, Journal of Cleaner Production, 137, pp. 567-578.

[5] Fysikopoulos A, Anagnostakis D, Salonitis K and Chryssolouris G, 2012, An empirical study of the energy consumption in automotive assembly, Procedia CIRP, 3, pp. 477-482.

[6] Garza-Reyes JA, Jacques GW, Lim MK, Kumar V and Rocha-Lona L, 2014, Lean and green-synergies, differences, limitations, and the need for six sigma in: proceedings of IFIP, International Conference on Advances in Production Management Systems, Springer, pp. 71-81.

[7] Garza-Reyes JA, Kumar V, Chaikittisilp S and Tan KH, 2018, The effect of lean methods and tools on the environmental performance of manufacturing organisations, International Journal of Production Economics, 200, pp. 170-180.

[8] Gupta V, Narayanamurthy G and Acharya P, 2018, Can lean lead to green? Assessment of radial tyre manufacturing processes using system dynamics modelling, Computers \& Operations Research, 89, pp. 284-306.

[9] Ibrahim IA, Mohamat SA, Amir A and Ghalib A, 2012, The effect of gas metal arc welding (GMAW) processes on different welding parameters, Procedia Engineering, 41, pp. 1502-1506.

[10] Keskin C, Asan U and Kayakutlu G, 2013, Value stream maps for industrial energy efficiency In: Assessment and Simulation Tools for Sustainable Energy Systems. Springer, 357-379.

[11] Kumar SS And Kumar MP, 2014, Cycle time reduction of a truck body assembly in an automobile industry by lean principles, Procedia Materials Science, 5, pp. 1853-1862.

[12] Kurdve M, Shahbazi S, Wendin M, Bengtsson C and Wiktorsson M, 2015, Waste flow mapping to improve sustainability of waste management: a case study approach, Journal of Cleaner Production, 98, pp. 304-315.

[13] Letete T, Guma M And Marquard A, 2010, Information on climate change in South Africa: greenhouse gas emissions and mitigation options, Energy Research Centre, Cape Town, University of Cape Town,

[14] Manjunath M, Prasad SH, Kumar KK and Puthran D, 2014, Value stream mapping: a lean tool, The International Journal Of Business \& Management, 2(4), pp. 100.

[15] Mohajan HK, 2017, Greenhouse gas emissions, global warming and climate change, In: Proceedings of 15th Chittagong Conference on Mathematical Physics, 2017. Jamal Nazrul Islam Research Centre for Mathematical and Physical Sciences (JNIRCMPS). 3.

[16] Mousavi S, Kara S And Kornfeld B, 2014, Energy efficiency of compressed air systems, Procedia CIRP, 15(0), pp. 313-318.

[17] Mula J, Peidro D and Poler R, 2010, The effectiveness of a fuzzy mathematical programming approach for supply chain production planning with fuzzy demand, International Journal of Production Economics, 128(1), pp. 136-143. 
[18] Müller E, Stock T And Schillig R, 2014, A method to generate energy value-streams in production and logistics in respect of time-and energy-consumption, Production Engineering, 8(1-2), pp. 243-251.

[19] Mvola B AND KAH P, 2017, Effects of shielding gas control: welded joint properties in GMAW process optimization, The International Journal of Advanced Manufacturing Technology, 88(9-12), pp. 2369-2387.

[20] Newman ST, Nassehi A, Imani-Asrai R and Dhokia V, 2012, Energy efficient process planning for CNC machining, CIRP Journal of Manufacturing Science and Technology, 5(2), pp. 127-136.

[21] NGuyen MN and Do NH, 2016, Re-engineering assembly line with lean techniques, Procedia CIRP, 40, pp. 590-595.

[22] Pampanelli AB, Found P and Bernardes AM, 2014, A lean \& green model for a production cell, Journal of Cleaner Production, 85, pp. 19-30.

[23] Rohani JM and Zahraee SM, 2015, Production line analysis via value stream mapping: a lean manufacturing process of color industry, Procedia Manufacturing, 2, pp. 6-10.

[24] Rother M AND Shook J, 2003, Learning to see: value stream mapping to add value and eliminate muda, Lean Enterprise Institute.

[25] Saidur R, Rahim N and Hasanuzzaman M, 2010, A review on compressed-air energy use and energy savings, Renewable and Sustainable Energy Reviews, 14(4), pp. 1135-1153.

[26] Singh B, Garg SK and Sharma SK, 2011, Value stream mapping: literature review and implications for Indian industry, The International Journal of Advanced Manufacturing Technology, 53(5-8), pp. 799-809.

[27] Torres Jr AS AND Gati AM, 2009, Environmental value stream mapping (EVSM) as sustainability management tool In: Proceedings of PICMET'09-2009 Portland International Conference on Management of Engineering \& Technology. IEEE, 1689-1698.

[28] Verrier B, Rose B And Caillaud E, 2016, Lean and green strategy: the lean and green house and maturity deployment model, Journal of Cleaner Production, 116, pp. 150-156.

[29] WiLls B, 2011, Green intentions: creating a green value stream to compete and win, CRC Press. 